Article

\title{
The Combined ASTER and MODIS Emissivity over Land (CAMEL) Global Broadband Infrared Emissivity Product
}

\author{
Michelle Feltz ${ }^{1, *(\mathbb{D}}$, Eva Borbas ${ }^{1}$, Robert Knuteson ${ }^{1}$, Glynn Hulley ${ }^{2} \mathbb{B}^{\mathbb{C}}$ and Simon Hook ${ }^{2}$ \\ 1 Space Science and Engineering Center, University of Wisconsin-Madison, Madison, WI 53706, USA; \\ eva.borbas@ssec.wisc.edu (E.B.); robert.knuteson@ssec.wisc.edu (R.K.) \\ 2 Jet Propulsion Laboratory, California Institute of Technology, Pasadena, CA 91109, USA; \\ Glynn.Hulley@jpl.nasa.gov (G.H.); Simon.J.Hook@jpl.nasa.gov (S.H.) \\ * Correspondence: michelle.feltz@ssec.wisc.edu
}

Received: 16 May 2018; Accepted: 22 June 2018; Published: 28 June 2018

\begin{abstract}
Infrared surface emissivity is needed for the calculation of net longwave radiation, a critical parameter in weather and climate models and Earth's radiation budget. Due to a prior lack of spatially and temporally variant global broadband emissivity (BBE) measurements of the surface, it is common practice in land surface and climate models to set BBE to a single constant over the globe. This can lead to systematic biases in the estimated net and longwave radiation for any particular location and time of year. Under the National Aeronautics and Space Administration's (NASA) Making Earth System Data Records for Use in Research Environments (MEaSUREs) project, a new global, high spectral resolution land surface emissivity dataset has recently been made available at monthly at 0.05 degree resolution since 2000. Called the Combined ASTER MODIS Emissivity over Land (CAMEL), this dataset is created by the merging of the MODIS baseline-fit emissivity database developed at the University of Wisconsin-Madison and the ASTER Global Emissivity Dataset (GED) produced at the Jet Propulsion Laboratory. CAMEL has 13 hinge points between 3.6-14.3 $\mu \mathrm{m}$ which are expanded to cover 417 infrared spectral channels within the same wavelength region using a principal component regression approach. This work presents the method for calculating BBE using the new CAMEL dataset. BBE is computed via numerical integration over the CAMEL High Spectral Resolution product for two different wavelength ranges-3.6-14.3 $\mu \mathrm{m}$ which takes advantage of the full, available CAMEL spectra and 8.0-13.5 $\mu \mathrm{m}$ which has been determined to be an optimal range for computing the most representative all wavelength, longwave net radiation. CAMEL BBE uncertainty estimates are computed, and comparisons are made to BBE computed from lab validation data for selected case sites. Variations of BBE over time and land cover classification schemes are investigated and converted into flux to demonstrate the equivalent error in longwave radiation which would be made by the use of a single, constant BBE value. Misrepresentations in BBE by 0.05 at $310 \mathrm{~K}$ corresponds to potential errors in longwave radiation of over $25 \mathrm{~W} / \mathrm{m}^{2}$.
\end{abstract}

Keywords: broadband emissivity; infrared; surface; land; radiation

\section{Introduction}

Infrared surface emission is needed for the calculation of both the Earth's radiation budget and the Earth's surface radiation budget [1]—two variables which are defined as Essential Climate Variables by the Global Climate Observing System (GCOS) [2]. Land surface emissivity is a measure of how closely Earth's land surface acts as a blackbody in emitting radiation to the atmosphere. Infrared land surface emissivity has long been known to contain spectral variations that vary across the globe [3]. 
These spectral variations are dependent upon vegetation cover, wetness, snow cover, and mineral composition of the soil including its particle size and compactness [4,5]. Knowledge of the temporal, spatial, and spectral variations in land surface emissivity is important for data assimilation of the hyperspectral infrared sounders [6,7]. Uncertainties in land surface model parameterizations in Numerical Weather Prediction (NWP) models can influence the state parameters in the atmospheric boundary layer and the forecast of severe weather [8].

NWP land surface models, e.g., the Noah Land Surface Model in the Weather Research and Forecasting model (WRF), characterize land surface emissivity in terms of constant broadband values which are multiplied by the Stefan-Boltzman constant and the surface temperature to the fourth power to estimate the surface leaving infrared flux [9]. Due to a previous lack of spatially and temporally varying global broadband emissivity (BBE) measurements, the use of simple parameterizations or a single constant, global BBE value was adopted as common practice $[10,11]$. Such approximations can lead to systematic biases in the estimated net radiation for any particular location and time of year. A study done by Zhou et al. [11] showed that on average over North Africa a decrease in soil emissivity of 0.1 could increase surface air temperature by $\sim 1 \mathrm{~K}$ and decrease upward longwave (LW) radiation by $8.1 \mathrm{Wm}^{-2}$.

Several efforts in the past have outlined methods to produce optimal BBE datasets using satellite infrared measurements [12-19]. Such methods have typically involved regression of BBE to measured narrowband emissivities and/or albedos from satellite instruments such as the Moderate Resolution Imaging Spectroradiometer (MODIS), Advanced Spaceborne Thermal Emission and Reflection Radiometer (ASTER), or the Advanced Very High Resolution Radiometer (AVHRR). Another method that has been used is the classification-based scheme, which defines BBE for various land surface classifications using laboratory based measurements. An example of this is the parameterizations of BBE that have been developed for input into models such as in Wilber et al. [20], where BBE values are provided for different infrared bands and International Geosphere-Biosphere Programme (IGBP) land cover classifications. Work has also been done to determine an optimal BBE wavelength range for computing the most representative all-wavelength net radiation [18,21]. Cheng et al. [18] found that the all-wavelength surface LW net radiation was best approximated using the wavelength range of 2.5-200 microns. They then established that out of a set of wavelength ranges, the BBE spectral range of 8-13.5 microns was optimal for computing the LW net radiation between 2.5 and 200 microns.

Under the National Aeronautics and Space Administration (NASA) Making Earth System Data Records for Use in Research Environments (MEaSUREs) project, a new global, land surface emissivity termed the Combined ASTER and MODIS Emissivity over Land (CAMEL) has been made available and is a part of the Unified and Coherent Land Surface Temperature and Emissivity Earth System Data Record [22-25]. This new dataset combines previously existing satellite emissivity datasets-those from the MODIS baseline-fit emissivity database (BF) developed at the University of Wisconsin-Madison (UW) and the ASTER Global Emissivity Dataset version 4 (GED v4) produced at the California Institute of Technology Jet Propulsion Laboratory (JPL) [26-29]. CAMEL leverages the ability of ASTER GED $\mathrm{v} 4$ to accurately estimate infrared emissivity in the thermal infrared region $(8-12 \mu \mathrm{m})$ and the ability of UW BF to provide information at select hinge points throughout the entire 3.6-12 $\mu \mathrm{m}$ infrared region, thereby combining the strengths of each dataset. The CAMEL product is available for the years $2000-2016$ for monthly mean, $0.05^{\circ}$, or $\sim 5 \mathrm{~km}$, spatial resolution for 13 hinge points within the 3.6-14.3 $\mu \mathrm{m}$ region. An uncertainty product is included which contains estimates of the total uncertainty in addition to the spatial, temporal, and algorithm variability for each of the 13 hinge points on the CAMEL $0.05^{\circ}$ grid $[22,23]$. A high spectral resolution (HSR) emissivity algorithm which extends the 13 hinge point product to 417 infrared spectral channels within the same $3.6-14.3 \mu \mathrm{m}$ region is also available. This CAMEL HSR algorithm provides an update to the previous, similarly constructed UWIREMIS HSR emissivity product which is produced using the UW BF emissivity dataset [26,30].

This study presents broadband emissivity calculations that make use of the MEaSUREs CAMEL emissivity version V001 and the CAMEL HSR algorithm. The BBE dataset described here provides 
the advantage that (1) it is consistent with the MEaSUREs HSR emissivity and (2) it does not require regression schemes-BBE can be calculated by simple numerical integration over the CAMEL HSR emissivity product. Monthly, $\sim 5 \mathrm{~km}$ resolution BBE is calculated over the globe for the years 2000-2016. BBE is computed for two different wavelength ranges-over the 3.6-14.3 $\mu \mathrm{m}$ region which uses the full available CAMEL wavelength region and the 8.0-13.5 $\mu \mathrm{m}$ region which has been determined to be an optimal range for computing the most representative all wavelength, longwave net radiation $[18,21]$. The physical reasoning for the choice of the $8.0-13.5 \mu \mathrm{m}$ is described by Ogawa and Schmugge [21] - they showed that outside the 8.0-13.5 $\mu \mathrm{m}$ region, assuming the surface temperature and near-surface air temperature are close, the difference between the surface temperature and brightness temperature of the downwelling atmospheric radiation is small. Thus, they argue only minor contributions to the net longwave radiation come from outside the 8.0-13.5 $\mu \mathrm{m}$ region [21]. This choice has been supported by other studies as well, e.g., Cheng et al. (2013) [18].

The dependence of BBE on skin temperature is demonstrated for five different case sites for both wavelength ranges. Uncertainty estimates of the CAMEL BBE and comparisons to BBE computed from the UWIREMIS product and lab validation spectra are made to characterize the accuracy of the CAMEL BBE product. Global maps of monthly and climatological results are shown for four months representing the four seasons. Lastly, statistics are calculated for various land surface types using the IGBP land cover categories and, BBE differences are then converted into fluxes to demonstrate the equivalent error in $L W$ radiation which would be made by the use of a single BBE value. Section 2 describes the data sources, Section 3 details the BBE calculation method, Section 4 contains results, and conclusions are made in Section 5.

\section{Data}

The CAMEL product version V001 is used in this study and is available from 2000 to 2016 at monthly, $0.05^{\circ}(\sim 5 \mathrm{~km})$ resolution for 13 hinge points within the 3.6-14.3 $\mu \mathrm{m}$ region [22-25]. It was created using the ASTER GED v4 and MODIS UW BF emissivity datasets as input. A standalone CAMEL HSR Algorithm which extends the 13 hinge point CAMEL product to 417 infrared spectral channels using a principal component regression approach is available with the dataset, as well as uncertainty estimates which are reported on the 13 hinge points. Additional details of the CAMEL dataset are available in Borbas et al. and Feltz et al. [22,23]. CAMEL is available from the NASA Land Processes Distributed Active Archive Center (LP DAAC) online at the following site: https: //lpdaac.usgs.gov/about/news_archive/release_nasa_measures_camel_5_km_products.

NASA's Earth Observing System MODIS instrument is used to provide monthly, global skin temperature and IGBP land cover classification on a $0.5^{\circ} \times 0.5^{\circ}$ and $0.25^{\circ} \times 0.25^{\circ}$ grid resolution, respectively. Specifically, the MOD11C3 skin temperature product, which is used in the calculation of BBE, is made available online by the NASA and United States Geological Survey (USGS) LP DAAC at the following site: https://lpdaac.usgs.gov/dataset_discovery / modis [31]. The land cover product MCD12Q1 is made available by the Global Land Cover Facility online at http:/ / glcf.umd.edu/data/lc/ and more information can be found in Friedl et al. and Channan et al. [32,33]. There are 17 land cover types as defined by the IGBP classifications, and these are used to characterize BBE behavior over different surface types.

\section{Methods}

The CAMEL broadband emissivity is calculated by using the HSR emissivity algorithm which extends the 13 hinge point CAMEL product to 417 contiguous spectral channels between 3.6 and $14.3 \mu \mathrm{m}$. The following equation is then used [18]:

$$
\varepsilon_{B B}=\frac{\int_{v_{1}}^{v_{2}} \varepsilon_{v} B_{v}\left(T_{s}\right) d v}{\int_{v_{1}}^{v_{2}} B_{v}\left(T_{S}\right) d v},
$$


where $\varepsilon_{v}$ is the CAMEL monthly, HSR emissivity product and $B_{v}$ is the Planck function at wavenumber $v$ and temperature $T_{s}$, which is the land surface temperature defined by the average of the day and night monthly MOD11C3 MODIS products. If no MODIS temperature is available, a default value of $290 \mathrm{~K}$ is used. There is anticipated to be minimal error due to this approximation of skin temperature- - this is based upon previous studies which have asserted that BBE is largely insensitive to variations of temperature that are within the typical range experienced on Earth [21], as well as analyses and discussions included below. A quality flag for the CAMEL BBE is defined that describes where the input temperature was taken from and is shown in Table 1. As mentioned, BBE values are calculated for two different wavelength ranges-the 3.6-14.3 $\mu \mathrm{m}$ region which covers the full extent of the CAMEL emissivity spectrum, and the 8.0-13.5 $\mu \mathrm{m}$ region. Lastly, CAMEL BBE uncertainty estimates are computed using a combination of the CAMEL HSR uncertainty product and Equation (1). Specifically, BBE is calculated for the CAMEL HSR product with both the uncertainty added and subtracted from it, and the difference of these is then divided by two to produce the uncertainty estimate.

Table 1. CAMEL broadband emissivity quality flag definition.

\begin{tabular}{cl}
\hline Value & \multicolumn{1}{c}{ Description } \\
\hline 0 & Good-BBE between 0.8-1.0 \\
1 & Good-no MODIS data, 290 K used as default skin temperature \\
2 & BBE outside 0.8-1.0 range \\
3 & BBE calculation failed \\
4 & No BBE calculation-no CAMEL coefficients available \\
5 & No BBE calculation-sea or inland water \\
\hline
\end{tabular}

\section{Results}

\subsection{CAMEL Broadband Emissivity}

Examples of the CAMEL 13 hinge point and HSR products with uncertainty for the month of January 2007 are shown overlaid in Figure 1 for five case study sites that represent different land surface types. The Namib Desert site is dominated by the quartz mineral (with traces of hematite), for which the spectral feature is clearly shown within the 8-9.5 $\mu \mathrm{m}$ region. The Yemen site represents a carbonate surface minerology type, and such areas are found primarily on the southern tip of the Arabian Peninsula. The Atmospheric Radiation Measurement (ARM) Southern Great Plains (SGP) site is located in Lamont, Oklahoma and represents a grass-covered, farmland surface type. The Greenland case study is representative of snow and ice-covered surfaces, and lastly, the Congo Forest site represents a moist, broadleaf forest of the subtropics/tropics. The overlaid emissivities in each panel of Figure 1 show how the CAMEL HSR product, through correlation with laboratory spectra, is able to add physical spectral variations in emissivity not apparent in the 13 hinge point product $[22,23]$.

Figure 2 shows how the January 2007 CAMEL BBE for the five sites varies with temperature for both the 8.0-13.5 and 3.6-14.3 $\mu \mathrm{m}$ ranges. The site with the highest sensitivity to skin temperature is the Namib Desert site, for which the 8.0-13.5 $\mu \mathrm{m}$ BBE decreases by $~ 0.0014$ for every $10 \mathrm{~K}$ increase in skin temperature. Overall the 3.6-14.3 $\mu \mathrm{m}$ BBE varies less with skin temperature than does the 8.0-13.5 $\mu \mathrm{m}$ BBE. The small, $\sim 0.002$ difference in BBE between the 220 and $320 \mathrm{~K}$ skin temperatures seen at the Greenland site implies that the errors produced by the use of a $290 \mathrm{~K}$ default skin temperature would lead to negligible errors for snow and ice-covered regions, which are the regions that would be most poorly represented by a $290 \mathrm{~K}$ skin temperature. 

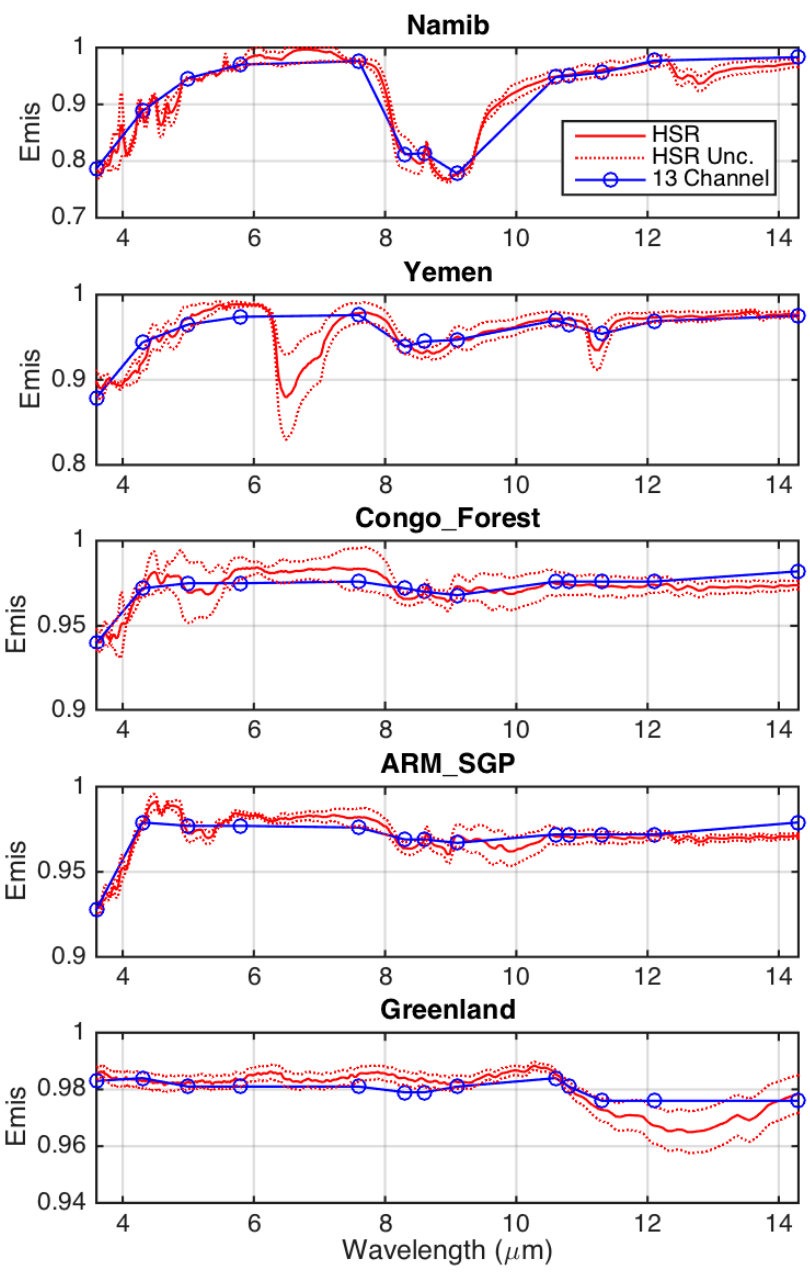

Figure 1. CAMEL emissivity for the 13 hinge points (blue open circles), 417 HSR channels (red line), and HSR uncertainty (red dotted lines) for January 2004 over the (from the top to bottom panel) Namib Desert (quartz), Yemen (carbonates), Congo (forest), Atmospheric Radiation Measurement Southern Great Plains (mixed agriculture), and Greenland (ice/snow) sites. Note changes in y-axis limits between panels.

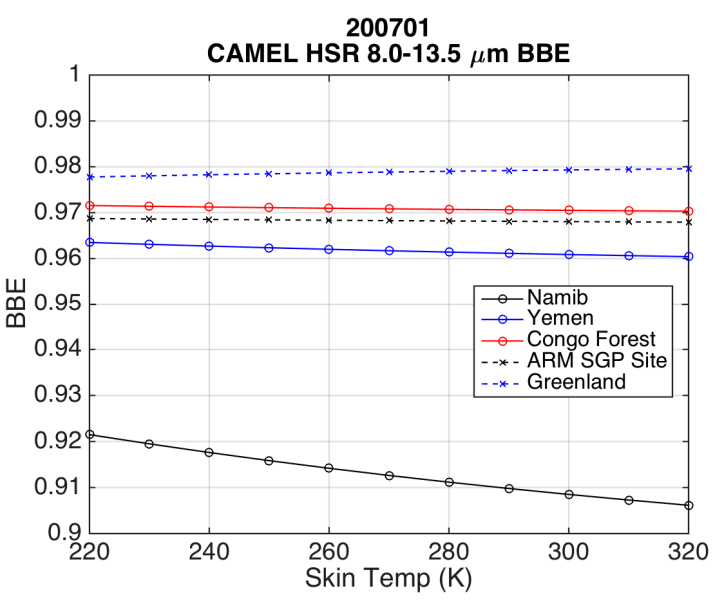

(a)

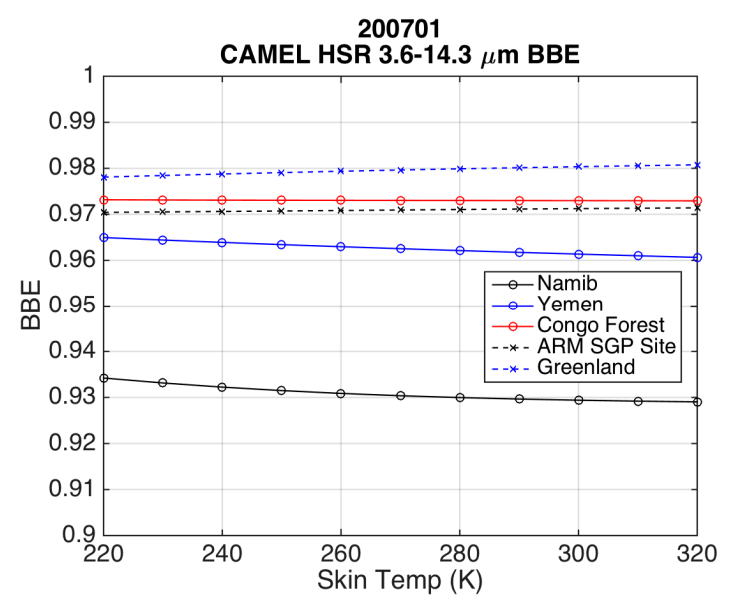

(b)

Figure 2. January 2007 CAMEL high spectral resolution (HSR) broadband emissivity (BBE) dependence on skin temperature for 5 different case study sites for (a) the 8.0-13.5 $\mu \mathrm{m}$ region and; (b) the 3.6-14.3 $\mu \mathrm{m}$ region. 
Uncertainty of the CAMEL BBE, in addition to BBE computed from CAMEL, lab validation spectra, and UWIREMIS product are shown for the five case sites in Table 2. These BBE are computed for the 8.0-13.5 $\mu \mathrm{m}$ region with the exception for the Namib site, which is computed over 8.0-13.0 $\mu \mathrm{m}$, since the lab data for that site does not extend beyond $13 \mu \mathrm{m}$. Uncertainty is largest for the Namib site at 0.0112 and smallest for the Greenland site at 0.0038. The CAMEL and lab BBE are in agreement within the CAMEL uncertainty for the Yemen, Congo, and ARM SGP site, and CAMEL BBE is less and more than the lab for the Greenland site and Namib sites respectively. For all sites except for Greenland, CAMEL BBE is in better agreement with the lab validation BBE than the UWIREMIS.

Table 2. CAMEL 8.0-13.5 $\mu \mathrm{m}$ BBE Uncertainty and Validation at Case Sites.

\begin{tabular}{ccccc}
\hline Site & CAMEL & CAMEL Uncertainty & Lab Data & UWIREMIS \\
\hline Namib $^{* *}$ & 0.9049 & 0.0112 & 0.8934 & 0.9182 \\
Yemen & 0.9609 & 0.0087 & 0.9616 & 0.9580 \\
Congo & 0.9716 & 0.0059 & 0.9767 & 0.9673 \\
ARM SGP & 0.9684 & 0.0045 & 0.9720 & 0.9667 \\
Greenland & 0.9775 & 0.0038 & 0.9831 & 0.9798 \\
\hline
\end{tabular}

** For Namib, lab data is not available for wavelengths larger than $13 \mu \mathrm{m}$, so BBE is computed over 8.0-13.0 $\mu \mathrm{m}$ for each the CAMEL, lab validation, and UWIREMIS.

Time series of the CAMEL 8.0-13.5 and 3.6-14.3 $\mu \mathrm{m}$ BBE for the five case sites shown in Figure 1 as well as for a seasonally snow-covered site in the Rocky Mountains (Mt. Massive) are shown in Figure 3. (Note $y$-axis scale change.) Overlaid on the CAMEL BBE time series is BBE computed from the UWIREMIS HSR emissivity product. Generally, the difference between the 8.0-13.5 and 3.6-14.3 $\mu \mathrm{m}$ BBE estimates is small, under 0.01 for both CAMEL and UWIREMIS. An exception exists for the Namib Desert site, where differences are seen to be just over 0.01 in BBE between the wavelength ranges. Differences between the CAMEL and UWIREMIS BBE vary over time with the newer CAMEL dataset showing more long-term stability. The Namib site shows an overall temporally constant difference of $\sim 0.01$ between the CAMEL and UWIREMIS BBE; however, the Yemen site shows a large increase in the CAMEL minus UWIREMIS BBE over the 2000-2016 time period. This decrease in the UWIREMIS product is attributed to the MODIS product input to the UWIREMIS HSR algorithm, which is known to degrade over this time period due to intrinsic algorithm issues. The CAMEL BBE for this site is more stable due to the inclusion of ASTER GED v4 emissivity data that is an input for the CAMEL product. This site example, as well as others like the Greenland site where sporadic variations are seen in UWIREMIS BBE between 2003 and 2007, imply that the CAMEL HSR emissivity is an improvement upon the UWIREMIS product. While the Greenland and Namib Desert sites show the CAMEL BBE to be quite constant over time, obvious seasonal dependencies are seen in both the ARM SGP and Rocky Mountain site CAMEL BBE. This is expected, as the Northern Hemisphere mid-latitudes experience large changes in snow and vegetation cover over the year. Changes in BBE over season are seen to be $\sim 0.01$ and $\sim 0.02$ for the ARM SGP and Rocky Mountain site respectively. Such regions would suffer from the greatest amount of error from the use of a temporally constant BBE value in modeling purposes.

Figure 4 shows the global CAMEL BBE results as maps for the month of January 2007 for both the $8-13.5$ and 3.6-14.3 $\mu \mathrm{m}$ regions. The wider 3.6-14.3 $\mu \mathrm{m}$ range produces larger BBE magnitudes but is otherwise qualitatively similar to the $8.0-13.5 \mu \mathrm{m}$ range. The Saharan Desert, barren regions of Australia, and Tibetan Plateau have markedly lower BBE values, while snow and ice-covered regions have the largest BBEs. The bottom panel shows a cutout of the 8.0-13.5 $\mu \mathrm{m}$ BBE over northeast Africa and the Arabian Peninsula and highlights the detail that the $5 \mathrm{~km}$ resolution CAMEL product is able to pick up, e.g., the Nile River and distinct changes in surface mineralogy within the Sahara Desert. For the remainder of the analyses in this paper, the $8-13.5 \mu \mathrm{m}$ range is used to illustrate the BBE results. 
As previously mentioned, broadband emissivity values used in some land surface or radiative models are set to a single, constant value over the globe and over time. To illustrate the magnitude and spatial distribution of error in BBE that is made by such an approximation, Figure 5 shows maps of 8.0-13.5 $\mu \mathrm{m}$ January 2007 CAMEL BBE minus various example constants, ranging from 0.96 to 0.98. Even for the constant 0.97 , which appears to globally offer the closest match for the January BBE, differences of over 0.05 are seen in various localized areas as well as over the majority of the Saharan Desert and Arabian Peninsula where differences exceed 0.08.

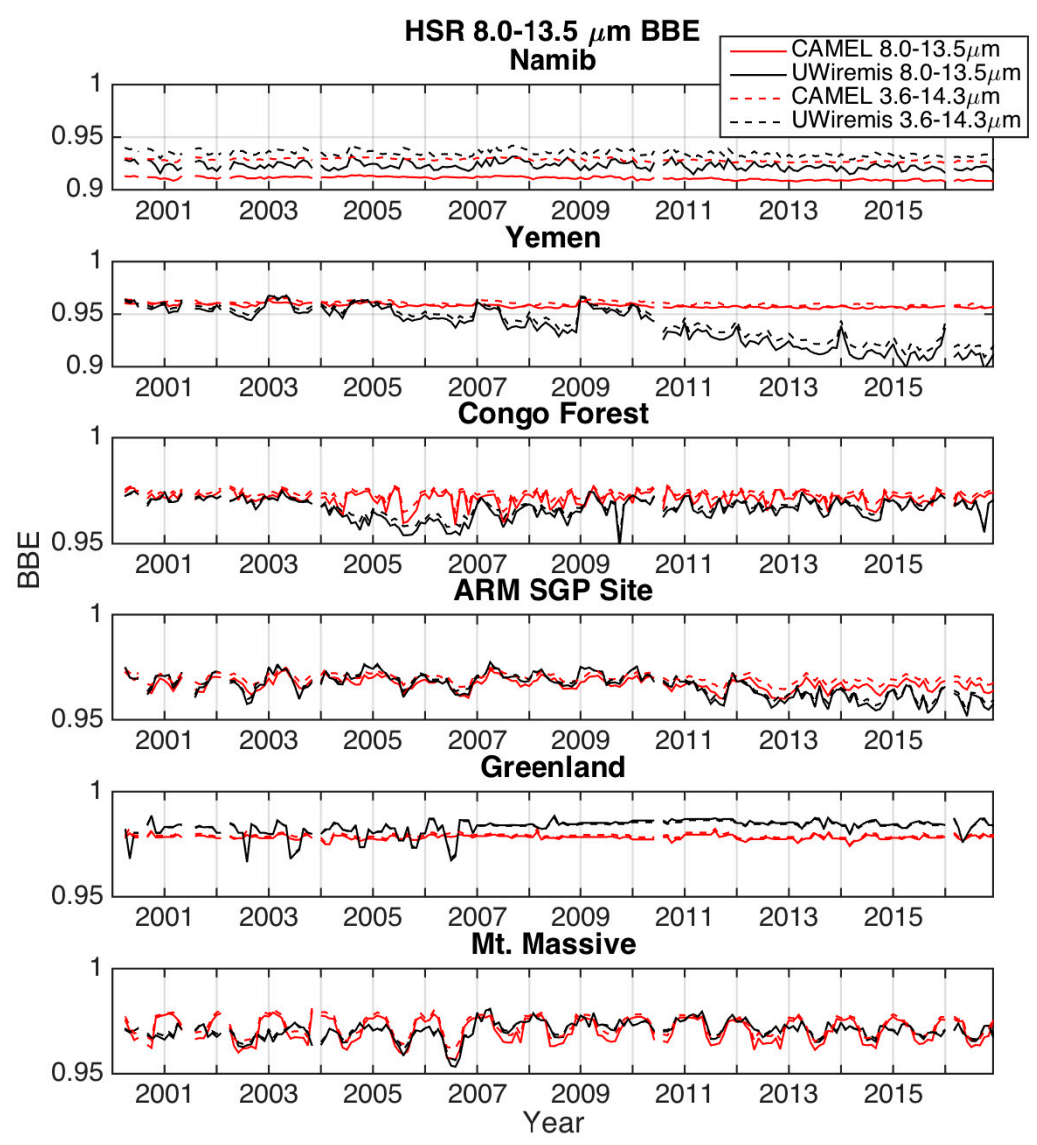

Figure 3. Time series of monthly average $0.5^{\circ} \times 0.5^{\circ}$ CAMEL (red) and UWIREMIS (black) 8.0-13.5 $\mu \mathrm{m}$ (solid) and 3.6-14.3 $\mu \mathrm{m}$ (dashed) BBE for five sites (see Figure 1 for single month of corresponding emissivity spectra).

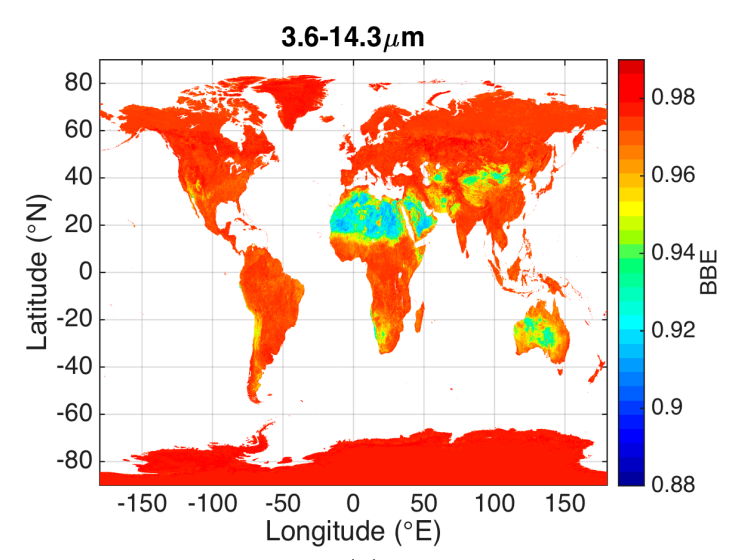

(a)



(b)

Figure 4. Cont. 




(c)

Figure 4. January 2007 CAMEL BBE for (a) 3.6-14.3 $\mu \mathrm{m}$ and; (b) 8.0-13.5 $\mu \mathrm{m}$ with (c) cutout over the eastern Sahara Desert and Arabian Peninsula for the 8.0-13.5 $\mu \mathrm{m}$ BBE.



(a)



(b)

Figure 5. Cont. 


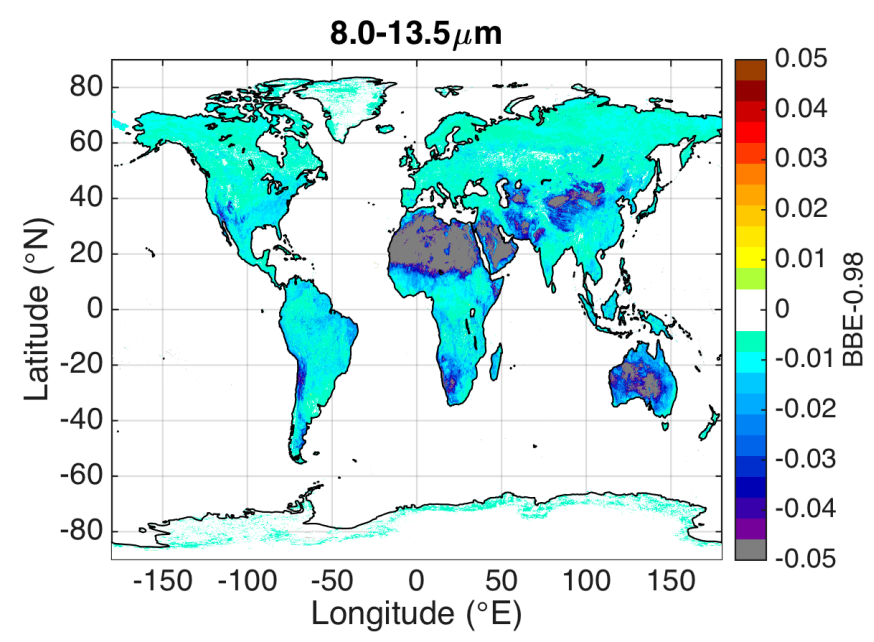

(c)

Figure 5. CAMEL 8.0-13.5 $\mu \mathrm{m}$ January 2007 BBE minus (a) 0.96; (b) 0.97 and; (c) 0.98.

Monthly climatologies of the CAMEL 8.0-13.5 $\mu \mathrm{m}$ BBE over the years 2000-2016 are calculated and shown for 4 months that represent different seasons in Figure 6. While BBE does not change dramatically from season to season, there are noticeable changes over the Northern Hemisphere polar and mid-latitudes due mostly to vegetation phenology and snow freeze/melt cycles. Figure 7 shows the standard deviation of the CAMEL BBE over the entire the 2000-2016 record and highlights the regions of highest variability over time. In contrast to the differences between the subpanels in Figure 6 which show the average conditions for single months, Figure 7 shows the variability over all of the individual months of the CAMEL record. Regions of increased standard deviations include the Sahel and southern tip of Africa (likely due to intensive biomass burning over the Sub-Saharan Africa region), Australia, and the Steppes of Central Asia, where standard deviations reach up to 0.025. Mountainous regions including the Andes on the southwestern South American coastline and the Rocky Mountains of the US show larger variabilities as well, reaching over 0.01 in some areas. These areas would be most poorly represented by a single BBE constant over time.

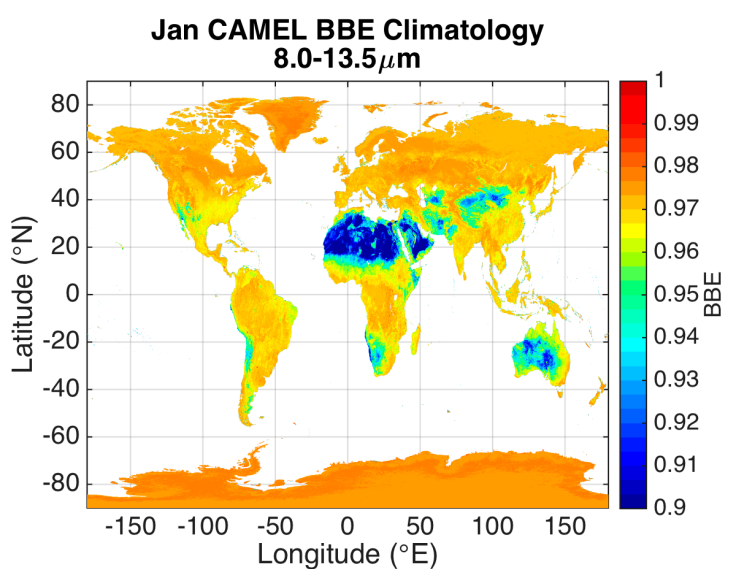

(a)

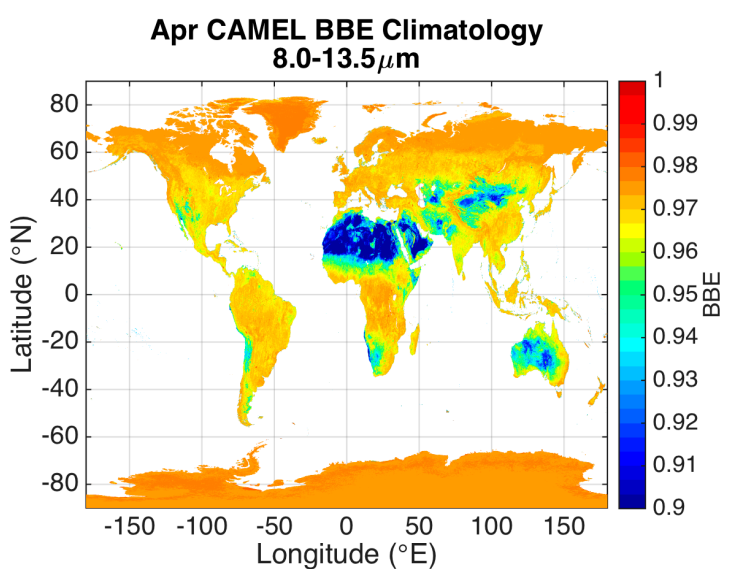

(b)

Figure 6. Cont. 


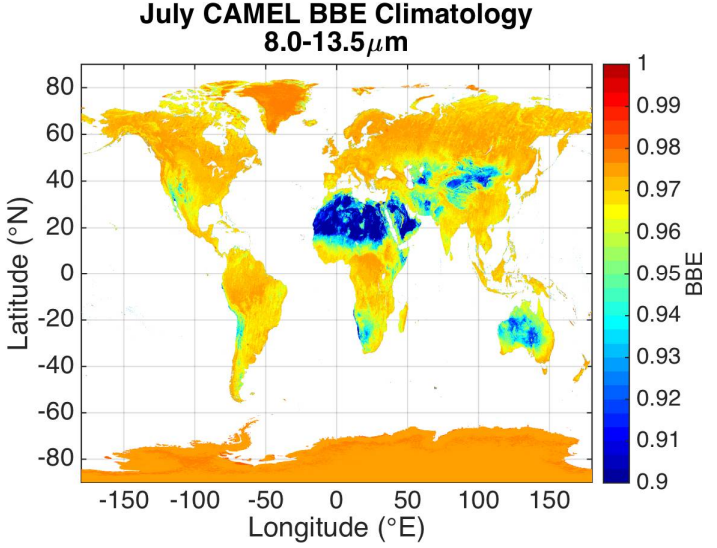

(c)

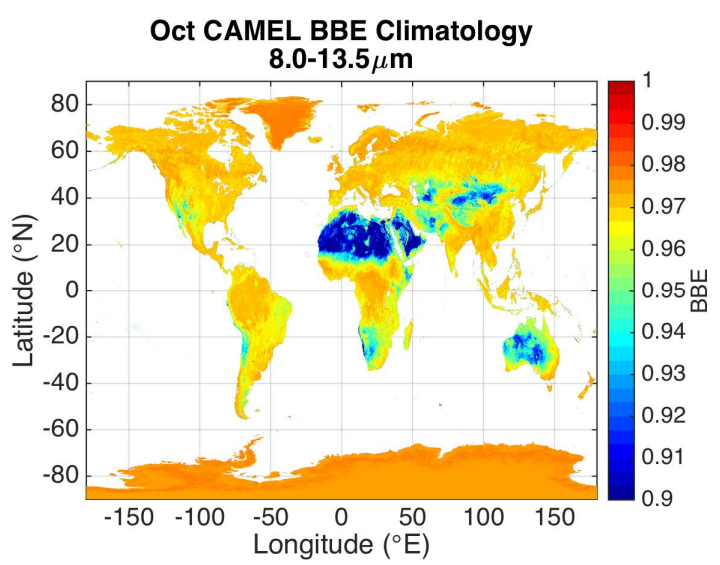

(d)

Figure 6. Monthly climatology of CAMEL 8.0-13.5 $\mu \mathrm{m}$ BBE over 2000-2016 for the month of (a) January; (b) April; (c) July and; (d) October.

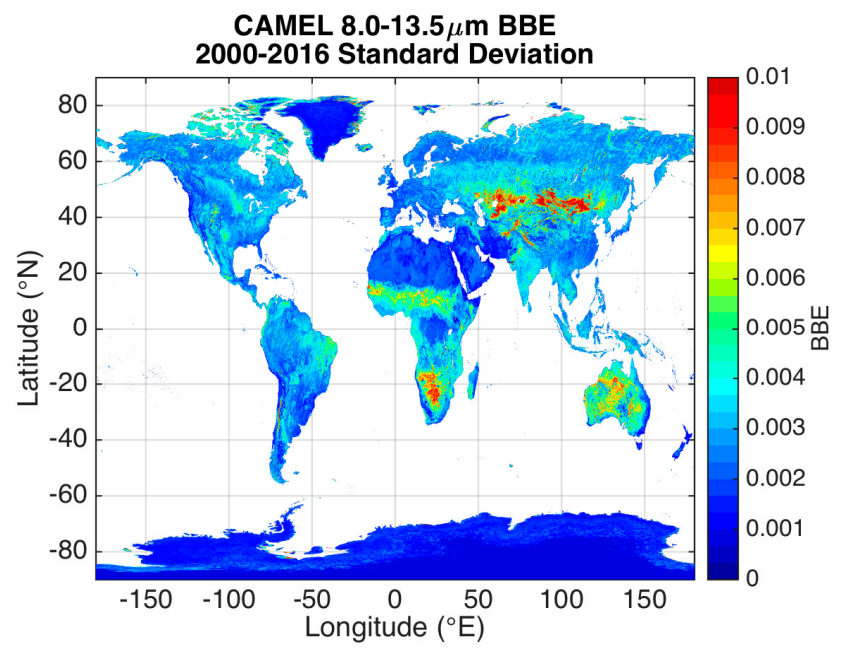

Figure 7. Standard deviation of monthly, 8.0-13.5 $\mu \mathrm{m}$ CAMEL BBE over the years 2000-2016 highlights geographic regions which have larger temporal variations in BBE.

\subsection{BBE by Land Type and Climate Regime}

To further investigate how BBE changes with surface cover type, statistics are calculated over IGBP land cover classifications listed in Table 3. To calculate the statistics, IGBP categories are mapped to the CAMEL $0.05^{\circ}$ resolution latitude and longitude grid. Since the IGBP categories are defined on a $0.25^{\circ}$ grid, they are interpolated to the higher CAMEL resolution. Yearly updates of IGBP land cover are available for 2002-2012, so the categories for the year 2012 were used for IGBP statistics over the years 2012-2016.

For each month and land cover category, the mean, $\mu$, standard deviation, $\sigma$, and uncertainty of the mean, $\mu_{\text {unc }}$, is calculated. Uncertainty of the mean is calculated as follows:

$$
\mu_{\mathrm{unc}}=\sigma / \sqrt{ }(\mathrm{N})
$$

where $\mathrm{N}$ is the number of samples; however, the uncertainty of the mean value is found to be negligible so is not shown in figures.

Figure 8 shows time series of the monthly mean 8.0-13.5 $\mu \mathrm{m}$ BBE for several IGBP categories. Overlaid on the time series are monthly means bounded by monthly standard deviations. Categories with higher changes in mean BBE throughout the year include grassland, cropland, open shrubs, wetland, 
and needle forests. This makes physical sense as the grassland, cropland, wetland, and needle forests land cover categories are either dominantly located in the Northern Hemisphere or have significant portions of their coverage in the Northern Hemisphere where land cover changes significantly with the seasons and associated snow coverage. Larger monthly standard deviations, which indicate the land cover types that are not as well represented by a single, constant BBE value, are seen for the barren/sparse vegetation, grassland, and open shrub categories. Closer inspection of various time series, particularly for the wetland, evergreen needle forest and woody savanna, reveals an apparent change in the magnitude of the seasonal oscillation of the time series around the year 2007. This change in the time series behavior is likely attributable to the 2007 version change in the MODIS product which is used as input into the CAMEL emissivity. The update in the MODIS product from Collection 4.0 to 4.1 was made for a change in the way clouds are dealt with in the processing.

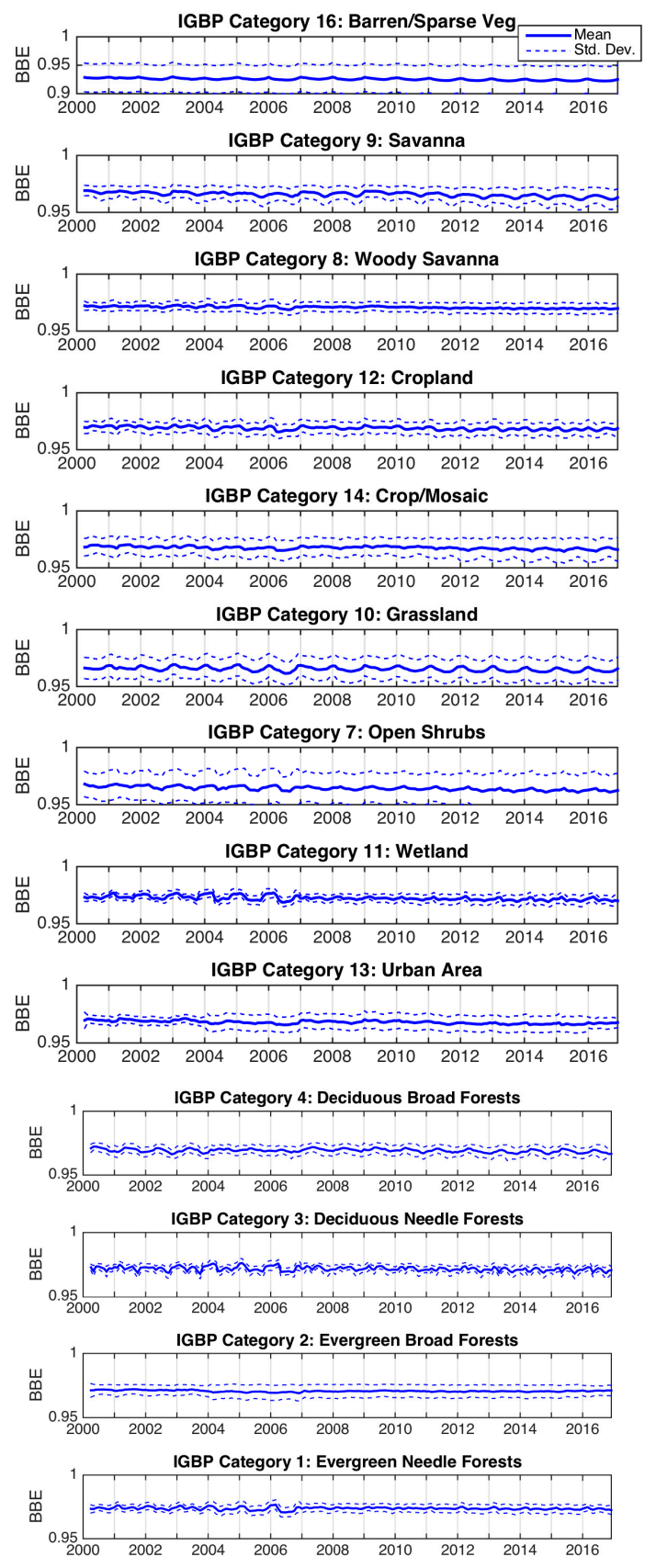

Figure 8. Time series of CAMEL 8.0-13.5 $\mu \mathrm{m}$ BBE statistics by IGBP land cover classifications. Note the $y$-axis limit is different for the top panel. 
A summary of the CAMEL 8-13.5 $\mu \mathrm{m}$ BBE over IGBP categories is given in Table 3, which contains the average BBE over IGBP categories for each monthly climatology of the CAMEL product. The associated number of samples are listed in Table 4. For this analysis, the IGBP categories for the year 2009 were chosen for computing statistics for the 2000-2016 CAMEL climatology. While the climatological averaging over multiple months of the CAMEL record mixes BBE values from different land cover categories, as land cover and land use change from year to year, the IGBP statistics for the CAMEL climatology give an approximate snapshot of how the 8.0-13.5 $\mu \mathrm{m}$ BBE changes over IGBP category and by season. Variation in BBE values over the land cover categories is larger than the month to month variation for a specific category by an order of magnitude. The grassland category experiences the largest change in BBE over seasons, but the difference is only 0.005 in magnitude. This is roughly equivalent to the CAMEL BBE uncertainty of the forested Congo and grassland/mixed agriculture of the ARM SGP sites (0.0059 and 0.0045 respectively), whereas the Yemen and Namib sites have larger uncertainties at 0.0087 and 0.0112 respectively and Greenland as a smaller uncertainty at 0.0038. Differences over land categories are seen to be as large as 0.05, larger than any of the site uncertainties. These differences in emissivity are shown as differences in LW radiation for three different skin temperatures in Table 5. The values in Table 5 are computed using the following equation:

$$
F=\varepsilon_{B B} \sigma T^{4}
$$

where $\sigma$ is the Stefan-Boltzmann constant and is equal to $5.67 \times 10^{-8} \mathrm{~W} / \mathrm{m}^{2} \mathrm{~K}^{4}, T$ is the skin temperature, $\varepsilon_{B B}$ is the broadband emissivity (or BBE perturbation), and $F$ is the $\mathrm{LW}$ radiation values reported in Table 5. Misrepresentations in BBE by 0.05 correspond to misrepresentations of LW radiation by $\sim 8$ to $37 \mathrm{~W} / \mathrm{m}^{2}$ for skin temperatures of 230 to $340 \mathrm{~K}$. If accounting for differences of these magnitudes is proved to be important for various surface modeling endeavors, then Table 3 for the 8-13.5 $\mu \mathrm{m}$ band could be used as a simple parameterization of infrared surface BBE values.

Table 3. Average CAMEL 2000-2016 monthly climatology BBE for the 8-13.5 $\mu \mathrm{m}$ region for IGBP land cover categories.

\begin{tabular}{lcccccccccccc}
\hline & Jan & Feb & Mar & Apr & May & June & July & Aug & Sept & Oct & Nov & Dec \\
\hline 1: Evergreen Needle & 0.974 & 0.975 & 0.975 & 0.974 & 0.973 & 0.973 & 0.974 & 0.974 & 0.973 & 0.973 & 0.973 & 0.974 \\
2: Evergreen Broad & 0.97 & 0.97 & 0.97 & 0.97 & 0.97 & 0.971 & 0.971 & 0.971 & 0.971 & 0.971 & 0.971 & 0.971 \\
3: Deciduous Needle & 0.972 & 0.972 & 0.974 & 0.973 & 0.97 & 0.972 & 0.973 & 0.972 & 0.971 & 0.969 & 0.972 & 0.972 \\
4: Deciduous Broad & 0.968 & 0.969 & 0.969 & 0.97 & 0.971 & 0.971 & 0.97 & 0.969 & 0.969 & 0.969 & 0.968 & 0.968 \\
5: Mixed Forest & 0.971 & 0.972 & 0.972 & 0.971 & 0.971 & 0.972 & 0.973 & 0.972 & 0.972 & 0.971 & 0.97 & 0.97 \\
6: Closed Shrubs & 0.964 & 0.964 & 0.964 & 0.966 & 0.966 & 0.964 & 0.963 & 0.963 & 0.963 & 0.964 & 0.965 & 0.964 \\
7: Open Shrubs & 0.965 & 0.965 & 0.965 & 0.966 & 0.964 & 0.963 & 0.963 & 0.963 & 0.962 & 0.963 & 0.964 & 0.964 \\
8: Woody Savanna & 0.971 & 0.971 & 0.971 & 0.971 & 0.971 & 0.971 & 0.971 & 0.97 & 0.97 & 0.97 & 0.971 & 0.971 \\
9: Savanna & 0.967 & 0.967 & 0.967 & 0.967 & 0.967 & 0.967 & 0.966 & 0.966 & 0.965 & 0.964 & 0.965 & 0.966 \\
10: Grassland & 0.968 & 0.968 & 0.966 & 0.965 & 0.965 & 0.964 & 0.963 & 0.963 & 0.964 & 0.964 & 0.965 & 0.967 \\
11: Wetland & 0.973 & 0.974 & 0.975 & 0.974 & 0.971 & 0.971 & 0.972 & 0.972 & 0.971 & 0.971 & 0.972 & 0.973 \\
12: Cropland & 0.97 & 0.97 & 0.969 & 0.968 & 0.968 & 0.968 & 0.969 & 0.969 & 0.969 & 0.968 & 0.968 & 0.969 \\
13: Urban Area & 0.968 & 0.968 & 0.967 & 0.967 & 0.968 & 0.967 & 0.967 & 0.967 & 0.967 & 0.967 & 0.967 & 0.968 \\
14: Crop/Mosaic & 0.968 & 0.968 & 0.967 & 0.966 & 0.967 & 0.968 & 0.968 & 0.968 & 0.969 & 0.968 & 0.968 & 0.968 \\
15: Snow \& Ice & 0.975 & 0.975 & 0.976 & 0.976 & 0.976 & 0.975 & 0.974 & 0.974 & 0.975 & 0.976 & 0.975 & 0.975 \\
16: Barren/Sparse Veg & 0.927 & 0.927 & 0.925 & 0.925 & 0.925 & 0.924 & 0.924 & 0.924 & 0.924 & 0.925 & 0.925 & 0.926 \\
\hline
\end{tabular}

Table 4. Number of samples for the average BBE climatology statistics over IGBP categories shown in Table 2.

\begin{tabular}{lc}
\hline \multicolumn{1}{c}{ IGBP Category } & Number of Samples \\
\hline 1: Evergreen Needle Forests & 179,000 \\
2: Evergreen Broad Forests & 454,500 \\
3: Deciduous Needle Forests & 94,500 \\
4: Deciduous Broad Forests & 43,400 \\
5: Mixed Forest & 492,200 \\
\hline
\end{tabular}


Table 4. Cont.

\begin{tabular}{lc}
\hline \multicolumn{1}{c}{ IGBP Category } & Number of Samples \\
\hline 6: Closed Shrubs & 1400 \\
7: Open Shrubs & $1,184,900$ \\
8: Woody Savanna & 418,000 \\
9: Savanna & 361,900 \\
10: Grassland & 876,300 \\
11: Wetland & 46,000 \\
12: Cropland & 507,000 \\
13: Urban Area & 3300 \\
14: Crop/Mosaic & 277,300 \\
15: Snow \& Ice & 367,700 \\
16: Barren/Sparse Vegetation & 695,300 \\
\hline
\end{tabular}

Table 5. Changes in LW radiation shown for various skin temperatures and changes in BBE.

\begin{tabular}{cccc}
\hline Representation & Emissivity (-) & Skin Temperature (K) & LW Radiation (W/m $\left.\mathbf{m}^{\mathbf{2}}\right)$ \\
\hline Change between months & 0.005 & 230 & 0.79 \\
Change between months & 0.005 & 310 & 2.62 \\
Change between months & 0.005 & 340 & 3.79 \\
Change in land cover & 0.05 & 230 & 7.9 \\
Change in land cover & 0.05 & 310 & 26.1 \\
Change in land cover & 0.05 & 340 & 37.89 \\
\hline
\end{tabular}

\section{Conclusions}

This study presented and applied a method for calculating infrared surface broadband emissivity estimates from the recently released MEaSUREs CAMEL version V001 emissivity dataset (https: / / ezid.lib.purdue.edu/id/doi:10.21231/S2PP8H). In comparison to previous methods that are based upon regression techniques using satellite narrow band channels, this method takes advantage of the CAMEL high spectral resolution emissivity product across the full 3.6-14.3 micron infrared spectrum and directly integrates Equation (1) to obtain BBE estimates. BBE calculations were performed for two wavelength ranges: (1) the full CAMEL 3.6-14.3 $\mu \mathrm{m}$ range and (2) the 8.0-13.5 $\mu \mathrm{m}$ range. The first range was used to take advantage of the full, available high spectral resolution CAMEL spectrum. The second range was selected based on work of previous studies [18,21]. Both Ogawa and Schmugge [21] and Cheng et al. [18] found that from various wavelength ranges studied, BBE over the 8.0-13.5 $\mu$ m range was optimal for computing all wavelength LW net radiation, which is a key parameter in radiation models and energy budgets.

For the case sites shown, BBE was found to be generally insensitive to skin temperature, with the exception of the Namib Desert site, for which a $\sim 0.0014$ decrease in BBE was seen for every $10 \mathrm{~K}$ increase in skin temperature. BBE from CAMEL were compared to those from lab validation spectra and were in agreement with them within the CAMEL BBE uncertainty for 3 of the sites-the Yemen (carbonate), Congo (forested), and ARM SGP (mixed agriculture). The Namib (quartz) lab data had a smaller BBE (by 0.0115) and the Greenland (snow/ice) lab data had a slightly larger BBE (by 0.0056) than CAMEL. Comparisons of CAMEL and UWIREMIS 8.0-13.5 $\mu \mathrm{m}$ BBE time series at selected sites showed the CAMEL HSR product to be an improvement upon the UWIREMIS HSR and that changes in BBE of up to $\sim 0.02$ can be experienced for a single location over the course of the year.

Differences of the monthly CAMEL BBE product from a single, global value illustrated the error from using single constants over time and space to represent BBE in radiation models. Differences from 0.98 , a constant which is known to be used in various models, revealed magnitudes greater than 0.05 , which is larger than the CAMEL BBE site uncertainties. Results showed more appropriate constant values could be chosen for specific applications using the global $5 \mathrm{~km}$ resolution CAMEL BBE dataset available from the authors upon request [34]. 
Statistics of CAMEL 8-13.5 $\mu \mathrm{m}$ BBE over IGBP land cover categories were shown as times series and revealed that the land cover categories changed by only 0.01 in BBE over an annual cycle. Changes in the BBE time series behavior were experienced prior to the year 2007 for some IGBP categories and suggest the influence of a MODIS product version change. IGBP land cover statistics were also calculated for the entire CAMEL records monthly climatologies, and are summarized in Table 3, an example parameterization of BBE which could be used in land surface models. Simple calculations of LW radiation corresponding to changes in monthly, climatological BBE over months ( 0.005 change in BBE) resulted in changes in LW radiation of $0.79-3.79 \mathrm{~W} / \mathrm{m}^{2}$ for skin temperatures of $230-340 \mathrm{~K}$, and changes over land cover categories ( 0.05 change in BBE) of $7.9-37.89 \mathrm{~W} / \mathrm{m}^{2}$ for similar skin temperatures. If a single BBE constant were used in land surface modeling, then systematic errors in the LW radiation of these magnitudes would occur.

Author Contributions: E.B., R.K., and M.F. conceived and designed the method, M.F. analyzed the data and wrote the paper, E.B. developed the software and data files, and G.H. and S.H. contributed their expertise.

Funding: This research was funded by NASA grant number NNX08AF8A.

Acknowledgments: Thanks are given to the reviewers of this work for their time and helpful comments.

Conflicts of Interest: The authors declare no conflict of interest.

\section{References}

1. Ramanathan, V. The Role of Earth Radiation Budget Studies in Climate and General Circulation Research. J. Geophys. Res. 1987, 92, 4075-4095. [CrossRef]

2. WMO (World Meteorological Organization). The Global Observing System for Climate: Implementation Needs GCOS-200; WMO: Geneva, Switzerland, 2016.

3. Prabhakara, C.; Dalu, G. Remote sensing of the surface emissivity at 9 micron over the globe. J. Geophys. Res. 1976, 81, 3719-3724. [CrossRef]

4. Salisbury, J.W.; D'Aria, D.M. Emissivity of terrestrial materials in the 3-5 $\mu \mathrm{m}$ atmospheric window. Remote Sens. Environ. 1992, 42, 83-106. [CrossRef]

5. Norman, J.M.; Divakarla, M.; Goel, N.S. Algorithms for extracting information from remote thermal-IR observations of the earth's surface. Remote Sens. Environ. 1995, 51, 157-168. [CrossRef]

6. Garand, L.; Buehner, M.; Wagneur, N. Background Error Correlation between Surface Skin and Air Temperatures: Estimation and Impact on the Assimilation of Infrared Window Radiances. J. Appl. Meteorol. Climatol. 2004, 43, 1853-1863. [CrossRef]

7. Dutta, S.K.; Garand, L.; Heilliette, S. Assimilation of Infrared Radiance Observations with Sensitivity to Land Surfaces in the Canadian Ensemble-Variational System. J. Appl. Meteorol. Climatol. 2016, 55, 561-578. [CrossRef]

8. Duda, J.D.; Wang, X.; Xue, M. Sensitivity of Convection-Allowing Forecasts to Land-Surface Model Perturbations and Implications for Ensemble Design. Mon. Weather Rev. 2017, 145, 2001-2025. [CrossRef]

9. Niu, G.Y.; Yang, Z.L.; Mitchell, K.E.; Chen, F.; Ek, M.B.; Barlage, M.; Kumar, A.; Manning, K.; Niyogi, D.; Rosero, E.; et al. The community Noah land surface model with multiparameterization options (Noah-MP): 1. Model description and evaluation with local-scale measurements. J. Geophys. Res. Atmos. 2011, 116. [CrossRef]

10. Jin, M.; Liang, S. An Improved Land Surface Emissivity Parameter for Land Surface Models Using. Am. Meterol. Soc. 2006, 19, 2867-2881.

11. Zhou, L.; Dickinson, R.E.; Tian, Y.; Jin, M.; Ogawa, K.; Yu, H.; Schmugge, T. A sensitivity study of climate and energy balance simulations with use of satellite-derived emissivity data over Northern Africa and the Arabian Peninsula. J. Geophys. Res. 2003, 108. [CrossRef]

12. Wang, K.; Wan, Z.; Wang, P.; Sparrow, M.; Liu, J.; Zhou, X.; Haginoya, S. Estimation of surface long wave radiation and broadband emissivity using moderate resolution imaging spectroradiometer (MODIS) land surface temperature/emissivity products. J. Geophys. Res. Atmos. 2005, 110, D11109. [CrossRef]

13. Tang, B.-H.; Wu, H.; Li, C.; Li, Z.-L. Estimation of broadband surface emissivity from narrowband emissivities. Opt. Express 2010, 19, 185-192. [CrossRef] [PubMed] 
14. Ogawa, K.; Schmugge, T.; Jacob, F.; French, A. Estimation of broadband land surface emissivity from multi-spectral thermal infrared remote sensing. Agron. EDP Sci. 2002, 22, 695-696. [CrossRef]

15. Ogawa, K.; Schmugge, T.; Rokugawa, S. Estimating broadband emissivity of arid regions and its seasonal variations using thermal infrared remote sensing. IEEE Trans. Geosci. Remote Sens. 2008, 46, 334-343. [CrossRef]

16. Liang, S.; Zhao, X.; Liu, S.; Yuan, W.; Cheng, X.; Xiao, Z.; Zhang, X.; Liu, Q.; Cheng, J.; Tang, H.; et al. A long-term Global LAnd Surface Satellite (GLASS) data-set for environmental studies. Int. J. Digit. Earth 2013, 6, 5-33. [CrossRef]

17. Ren, H.; Liang, S.; Yan, G.; Cheng, J. Empirical algorithms to map global broadband emissivities over vegetated surfaces. IEEE Trans. Geosci. Remote Sens. 2013, 51, 2619-2631. [CrossRef]

18. Cheng, J.; Liang, S.; Yao, Y.; Zhang, X. Estimating the optimal broadband emissivity spectral range for calculating surface longwave net radiation. IEEE Geosci. Remote Sens. Lett. 2013, 10, 401-405. [CrossRef]

19. Cheng, J.; Liang, S.; Yao, Y.; Ren, B.; Shi, L.; Liu, H. A comparative study of three land surface broadband emissivity datasets from satellite data. Remote Sens. 2014, 6, 111-134. [CrossRef]

20. Wilber, A.C.; Kratz, D.P.; Gupta, S.K. Surface Emissivity Maps for Use in Retrievals of Longwave Radiation Satellite; NASA Langley Research Center: Hampton, VA, USA, 1999.

21. Ogawa, K.; Schmugge, T. Mapping Surface Broadband Emissivity of the Sahara Desert Using ASTER and MODIS Data. Earth Interact. 2004, 8, 1-14. [CrossRef]

22. Borbas, E.; Hulley, G.; Feltz, M.; Knuteson, R.; Hook, S. The Combined ASTER MODIS Emissivity over Land (CAMEL) Part 1: Methodology and High Spectral Resolution Application. Remote Sens. 2018, 10, 643. [CrossRef]

23. Feltz, M.; Borbas, E.; Knuteson, R.; Hulley, G.; Hook, S. The Combined ASTER MODIS Emissivity over Land (CAMEL) Part 2: Uncertainty and Validation. Remote Sens. 2018, 10, 664. [CrossRef]

24. Hook, S. Combined ASTER and MODIS Emissivity for Land (CAMEL) Uncertainty Monthly Global 0.05Deg. V001; NASA EOSDIS Land Processes DAAC, USGS Earth Resources Observation and Science (EROS) Center: Souix Falls, SD, USA, 2017. Available online: https://lpdaac.usgs.gov/dataset_discovery/measures/ measures_products_table/cam5k30uc_v001 (accessed on 15 June 2018). [CrossRef]

25. Borbas, E.E.; Hulley, G.C.; Knuteson, R.O.; Feltz, M.L. MEaSUREs Unified and Coherent Land Surface Temperature and Emissivity (LST\&E) Earth System Data Record (ESDR): The Combined ASTER and MODIS Emissivity Database over Land (CAMEL) Users' Guide. 2017. Available online: https:/ /pdaac.usgs.gov/sites/ default/files/public/product_documentation/cam5k30_v1_user_guide_atbd.pdf (accessed on 7 May 2018).

26. Seemann, S.W.; Borbas, E.E.; Knuteson, R.O.; Stephenson, G.R.; Huang, H.L. Development of a global infrared land surface emissivity database for application to clear sky sounding retrievals from multispectral satellite radiance measurements. J. Appl. Meteorol. Climatol. 2007, 47, 108-123. [CrossRef]

27. Hulley, G.C.; Hook, S.J.; Abbott, E.; Malakar, N.; Islam, T.; Abrams, M. The ASTER Global Emissivity Dataset (ASTER GED): Mapping Earth's emissivity at 100 meter spatial scale. Geophys. Res. Lett. 2015, 42, 7966-7976. [CrossRef]

28. Borbas, E.E.; Seemann, S.W. Global Infrared Land Surface Emissivity: UW-Madison Baseline Fit Emissivity Database V2.0. 2007. Available online: http:/ / cimss.ssec.wisc.edu/iremis / (accessed on 15 June 2018).

29. Hulley, G.; Hook, S. AG5KMMOH: ASTER Global Emissivity Dataset, Monthly, 0.05 Degree, HDF5 V041; NASA EOSDIS Land Processes DAAC, USGS Earth Resources Observation and Science (EROS) Center: Souix Falls, SD, USA, 2016. Available online: https:/ /pdaac.usgs.gov/node/1123 (accessed on 15 June 2018). [CrossRef]

30. Borbas, E.E.; Ruston, B.C. The RTTOV UWiremis IR Land Surface Emissivity Module; EUMETAT NWP SAF, NWPSAF-MO-VS-042; EUMETSAT: Darmstadt, Germany, 2010.

31. Wan, Z. MOD11C3 MODIS/Terra Land Surface Temperature/Emissivity Monthly L3 Global 0.05Deg CMG. V006; NASA EOSDIS Land Processes DAAC, USGS Earth Resources Observation and Science (EROS) Center: Souix Falls, SD, USA, 2015. Available online: https://lpdaac.usgs.gov/dataset_discovery/modis/modis_ products_table/mod11c3_v006 (accessed on 15 June 2018). [CrossRef]

32. Friedl, M.A.; Sulla-Menashe, D.; Tan, B.; Schneider, A.; Ramankutty, N.; Sibley, A.; Huang, X. MODIS Collection 5 global land cover: Algorithm refinements and characterization of new datasets. Remote Sens. Environ. 2010, 114, 168-182. [CrossRef] 
33. Channan, S.; Collins, K.; Emanuel, W.R. Global Mosaics of the Standard MODIS Land Cover Type Data; University of Maryland and the Pacific Northwest National Laboratory: College Park, MD, USA, 2014.

34. Borbas, E.E.; Feltz, M.L.; Knuteson, R.O. Broad Band Emissivity derived from the MEaSUREs CAMEL V001 Database. UW-Madison Space Science and Engineering Center. Dataset. 2017. Available online: https:/ / ezid.lib.purdue.edu/id/doi:10.21231/S2PP8H (accessed on 15 June 2018). [CrossRef] 